\title{
Pruritus in Pregnancy
}

\author{
Aleksandra A. Stefaniak ${ }^{1,2} \cdot$ Manuel P. Pereira $^{1} \cdot$ Claudia Zeidler $^{1} \cdot$ Sonja Ständer $^{1}$
}

Accepted: 5 December 2021 / Published online: 21 February 2022

(c) The Author(s) 2022

\begin{abstract}
Pruritus in pregnancy is a common and burdensome symptom that may be a first sign of a pregnancy-specific pruritic disease (atopic eruption of pregnancy, polymorphic eruption of pregnancy, pemphigoid gestationis, and intrahepatic cholestasis in pregnancy) or a dermatosis coinciding with pregnancy by chance. Despite its high prevalence, pruritus is often underrated by physicians, and data regarding the safety profiles of drugs for pruritus are very limited. In this review, we illustrate the epidemiology, possible pathophysiology, clinical characteristics, and diagnostic workup of various pregnancy-related diseases and discuss antipruritic treatments. The prevalence of pruritus in pregnancy demonstrates the importance of symptom recognition and the need for an holistic approach, taking into account both the potential benefits for the patient and the potential risks to the fetus.
\end{abstract}

\section{Key Points}

Chronic pruritus, defined as an unpleasant sensation resulting in a need to scratch that lasts more than 6 weeks, is one of the major complaints during pregnancy.

Patients presenting with pruritus require an exact workup to establish the proper diagnosis.

The available treatment options require careful consideration of the potential benefits and risks for both the patient and the fetus in all cases.

\section{Introduction}

Chronic pruritus (CP), defined as an unpleasant sensation resulting in a need to scratch that lasts more than 6 weeks, is one of the major dermatological complaints during pregnancy. According to recent studies, $18-40 \%$ of pregnant patients experience pruritus [1-3]. In addition to being associated with pregnancy-specific conditions (atopic eruption of pregnancy [AEP], polymorphic

Aleksandra A. Stefaniak

aleksandra.stefaniak@student.umed.wroc.pl

1 Department of Dermatology and Center for Chronic Pruritus, University Hospital Münster, Von Esmarch Str 58, 48149 Münster, Germany

2 Department of Dermatology, Venereology and Allergology, Wroclaw Medical University, Wrocław, Poland eruption of pregnancy [PEP], pemphigoid gestationis [PG], and intrahepatic cholestasis in pregnancy [ICP]), pruritus may arise from dermatoses that coincidently develop during pregnancy, exacerbation of preexisting dermatoses, and physiological skin changes in pregnancy. This review aims to provide a comprehensive overview of dermatological and nondermatological conditions leading to $\mathrm{CP}$ in pregnancy. Clinical characteristics, diagnostic workup, and treatment options are discussed. When possible, we provide the US FDA letter label indicating pregnancy risk category (Table 1) [4]. The FDA letter grading system was retired and the Pregnancy and Lactation Labeling rule was instituted in 2015 to provide more qualitative information about medications in pregnancy. Therefore, drugs introduced after 2015 do not have letter labeling.

\section{Physiological Skin Changes in Pregnancy}

Pregnancy is associated with complex endocrinological, immunological, metabolic, and vascular changes that may influence every organ in the body, including the skin. Most of the changes that are important from the dermatological point of view are the result of hormonal alterations during gestation [5]. Almost all pregnant patients notice increased pigmentation (selective hyperpigmentation, secondary areola, linea nigra, and changes in nevi) [6]. Striae gravidarum, also known as stretch marks, occur in many pregnancies as a result of skin stretching combined with genetic and hormonal factors [5] and may be a cause of itch in pregnancy [7]. In addition, eccrine sweat gland and sebaceous gland activity increases and apocrine gland activity decreases in 
pregnancy [5], which also may contribute to pruritus in this group of patients. Knowledge of and the ability to distinguish between physiological changes of the skin in pregnancy is necessary for a proper differential diagnosis from pathological symptoms and to avoid unnecessary treatment [5].

\section{Pregnancy-Specific Pruritic Diseases}

\subsection{Atopic Eruption of Pregnancy}

\subsubsection{Definition and Epidemiology}

In 2005, Ambros-Rudolph et al. [8] introduced the term AEP as an umbrella concept for benign pruritic disorders of pregnancy (clinical case 1). AEP covers all patients formerly diagnosed with eczema of pregnancy, prurigo of pregnancy, and pruritic folliculitis of pregnancy and is the most common dermatosis of pregnancy [8]. This term covers both patients with exacerbation of preexisting atopic dermatitis (about $20 \%$ of patients) and patients experiencing skin manifestations for the first time during pregnancy [8, 9]. Patients with a family history of atopic dermatitis are at risk of developing AEP [9], but the disease is frequently idiopathic.

\section{Clinical Case 1}

Clinical presentation A 40-year-old gravida 2, para 1, presented in the 17th week of gestation with severely pruritic (worst pruritus intensity of the previous $24 \mathrm{~h}$ on the numerical rating scale: 10/10) papular skin lesions that first appeared during the first pregnancy, with partial remission after delivery and exacerbation within the first week of the second pregnancy. The pruritus was generalized with additional pinprick sensation causing severe impairment of quality of life (Dermatitis Life Quality Index score: 13, ItchyQoL score: 2.9).

Workup On admission, the patient presented with disseminated inflamed papules, scratch excoriations, and scars sparing the face and scalp areas. Both direct immunofluorescence and ELISA were negative, and no relevant abnormalities were found in routine laboratory blood tests. The patient had a positive medical history of allergic rhinoconjunctivitis, allergies to pollens, and positive family history (sister) of atopic eruption in pregnancy.

Treatment and course Based on the clinical presentation, the diagnosis of atopic eruption of pregnancy was made. Treatment included narrowband ultraviolet B phototherapy combined with systemic antihistamines (loratadine $10 \mathrm{mg}$ twice daily), topical glucocorticosteroids (diflucortolone valerate $0.1 \%$ cream), and sufficient emollient therapy. This treatment regimen brought some relief of the pruritus (20\% improvement).

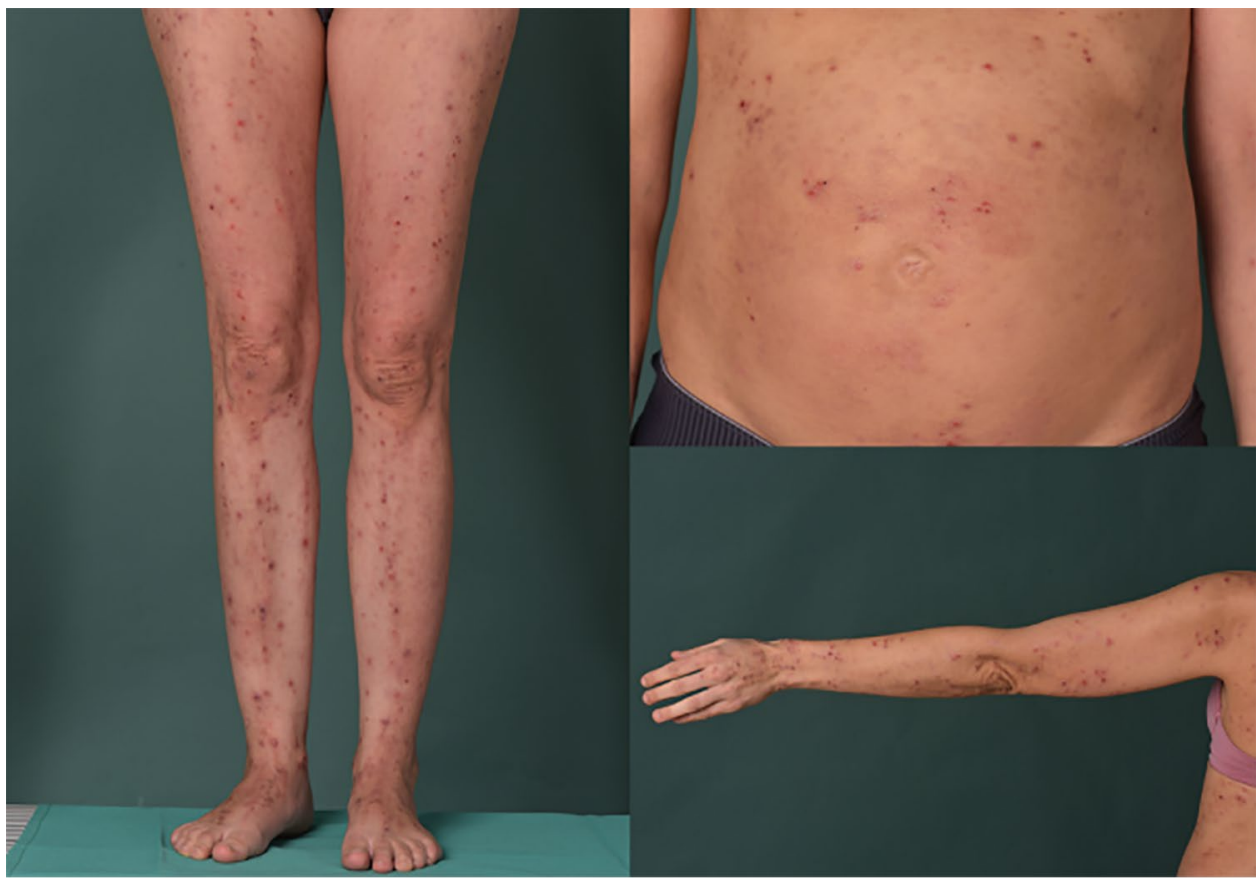


Table 1 US FDA letter labeling assessing pregnancy risk category [4]

\begin{tabular}{ll}
\hline Category & Description \\
\hline A & Adequate and well-controlled studies have failed to demonstrate risk to the fetus \\
B & Animal and reproduction studies have failed to demonstrate risk to the fetus, however, there are no adequate studies in humans \\
C & Animal reproduction studies have shown an adverse effect on the fetus, and there is a lack of studies in humans, but potential benefits \\
& may warrant use of the drug in pregnant patients despite potential risks \\
D & There is positive evidence of human fetal risk based on adverse reaction data based on studies in humans, but potential benefits may \\
& warrant use of the drug in pregnant patients despite potential risks \\
X & The risks involved in the use of the drug in pregnant patients clearly outweigh potential benefits \\
\hline
\end{tabular}

\subsubsection{Pathophysiology and Clinical Characteristics}

The pathogenesis of atopic exacerbation during pregnancy is not fully understood. As in atopic dermatitis, it is mainly considered to be a $\mathrm{T}$ helper type $2\left(\mathrm{Th}_{2}\right)$-driven disease [10] In pregnancy, a shift from $\mathrm{Th}_{1}$ - to $\mathrm{Th}_{2}$-mediated immunity occurs, which may lead to exacerbation of atopic dermatitis during pregnancy and the manifestation of AEP [8]. AEP usually starts earlier than other pregnancy-specific dermatoses, potentially even at the start of the pregnancy (Fig. 1). Recent studies have reported that patients without an atopic background are more likely to experience onset of the disease in the second or third trimester [11].

Ambros-Rudolph et al. [8] outlined two clinical presentations of AEP.
1. E-type (eczematous): classical distribution of lesions, including eczematous eruption on the face, neck, presternal region, and flexure sides.

2. P-type (prurigo): the presence of small, pruritic, erythematous, often grouped papules disseminated predominantly on the extensor surfaces of the extremities and the trunk.

$\mathrm{E}$ and $\mathrm{P}$ types often coexist, and a generalization of the lesions is possible. The secondary lesions include excoriations from scratching and bacterial or viral superinfection (e.g., eczema herpeticum).

\subsubsection{Diagnostic Workup}

A detailed medical history and comprehensive dermatological examination of the entire skin, including mucosae,

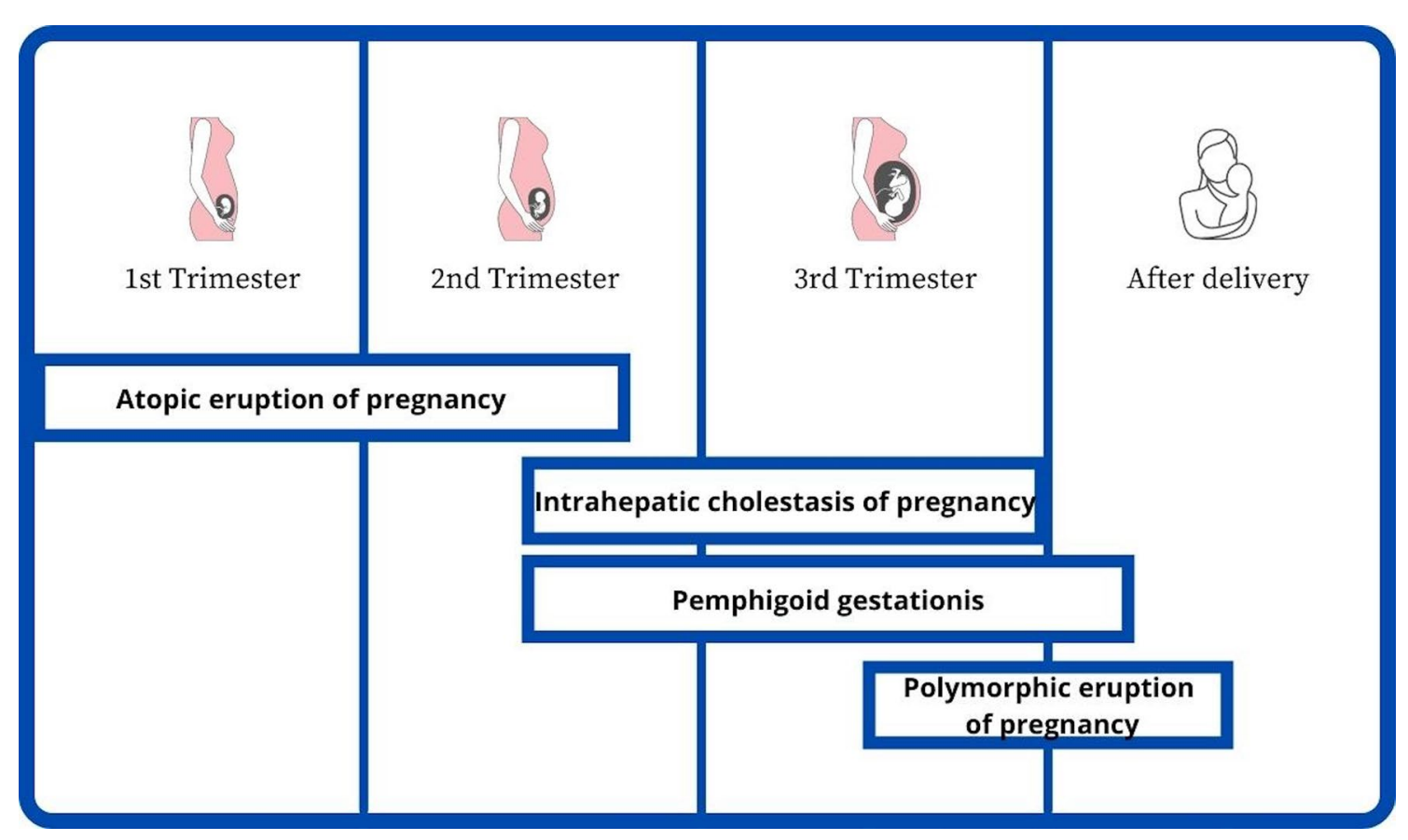

Fig. 1 Onset of pregnancy-specific pruritic dermatoses 
are necessary for a diagnosis of AEP. Patients with AEP usually present with early onset of eczematous/prurigo skin lesions (before the third trimester) with involvement of the trunk and limbs and may have atopic family or personal background. Histopathology is nonspecific and varies with the clinical type and stage of the disease. Therefore, skin biopsy is not indicated to make the diagnosis but may be helpful to exclude other causes of pruritus. Direct immunofluorescence (DIF) and indirect immunofluorescence results are negative. Laboratory test results indicate elevated serum immunoglobulin $\mathrm{E}$ (IgE) levels in about $30-70 \%$ of cases [12]. It is not clear whether IgE levels should be considered a diagnostic criterion as it has not been systematically studied in pregnancy [13]. Prick and patch tests are not recommended during pregnancy [14].

\subsubsection{Treatment}

Treatment of CP in AEP should focus on patient education and introducing a habit of sufficient emollient therapy, as this constitutes the basic dermatological therapy. Several compounds have been studied for their contribution to skin hydration and subsequent reduction in pruritus (Fig. 2) [15].

The second-line treatment of mild and moderate AEP involves topical glucocorticosteroids and systemic antihistamines. Narrowband ultraviolet B (UVB) is recommended as a second-line treatment in moderate and severe AEP, especially in early pregnancy [16]. For severe AEP manifesting with recalcitrant pruritus, short-term systemic treatment with glucocorticosteroids (prednisolone $0.5-2 \mathrm{mg} / \mathrm{kg} / \mathrm{day}$ ) may be considered.

In severe and very severe cases not responding to phototherapy and requiring prolonged courses of systemic glucocorticosteroids, immunosuppressive agents such as cyclosporine or azathioprine [17] should be introduced with caution and considering all possible risks and benefits. Azathioprine may be used off label in patients with severe uncontrolled AEP in whom other therapy options fail or when cyclosporine is contraindicated.

The anti-interleukin- 4 receptor (IL-4R)- $\alpha$ antibody dupilumab may constitute a future further therapy option for AEP. Dupilumab inhibits signaling via IL-4 and IL-13 by inhibiting both IL-4 type 1 and 2 receptors on various immune cells $[18,19]$. Data regarding its safety profile in case reports are promising $[20,21]$ but not yet sufficient. We recommend postponing the use of dupilumab in pregnancy until more experience and evidence becomes available.

\subsubsection{Prognosis and Fetal Risks}

The patient should be reassured of an excellent prognosis, as AEP is not associated with adverse fetal outcomes [22, 23]. However, depending on the parents' atopic background, the child might be predisposed to atopic eczema [24], and the disease might recur in subsequent pregnancies.
Fig. 2 Stepwise therapeutic approach of chronic pruritus in pregnancy based on the European guideline on chronic pruritus [15]. GCS glucocorticosteroids, $U V B$ ultraviolet B

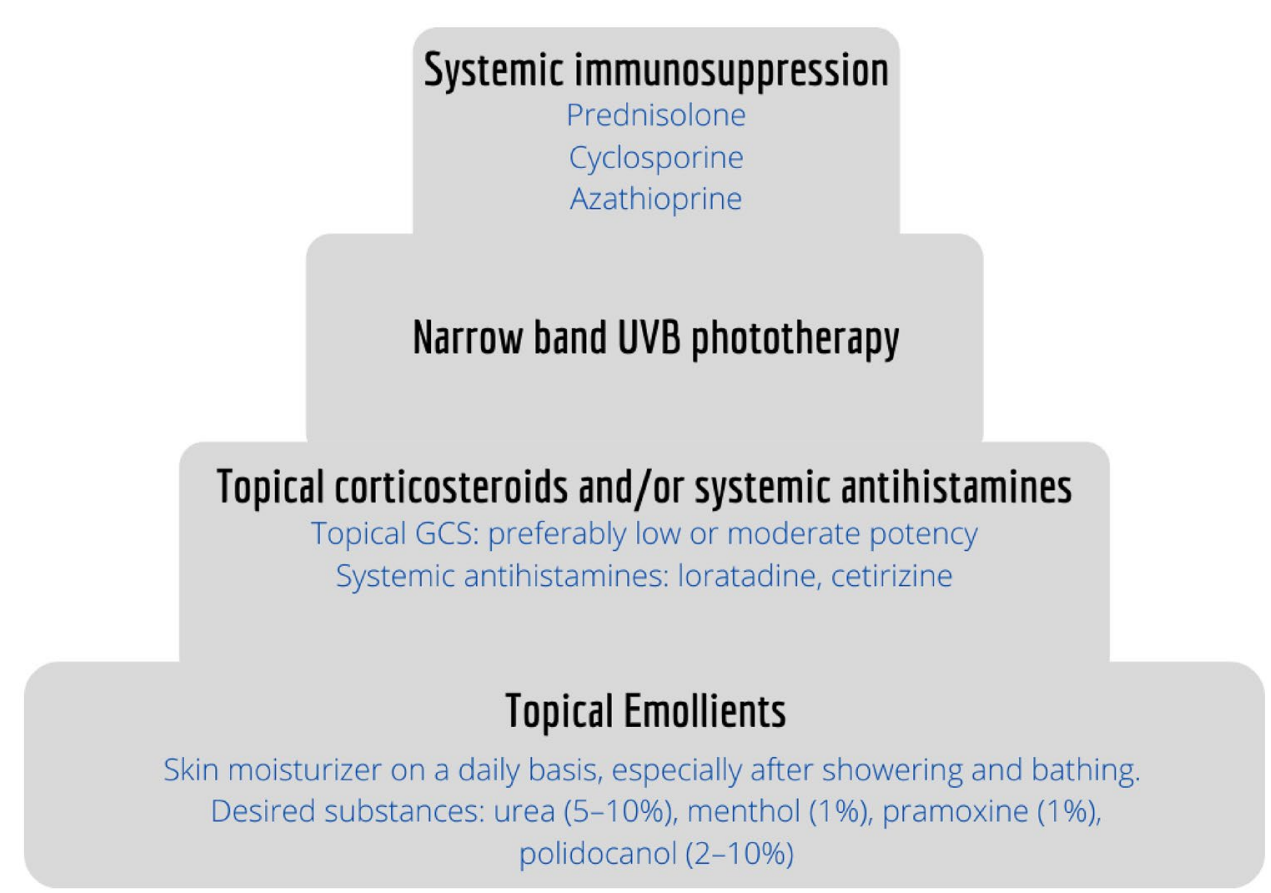




\subsection{Polymorphic Eruption of Pregnancy}

\subsubsection{Definition and Epidemiology}

PEP is also known as pruritic urticarial papules and plaques of pregnancy and is a benign self-limiting pruritic inflammatory disorder with an incidence of 1:120-1:300 pregnancies [25-28]. It usually occurs in the third trimester of pregnancy or immediately postpartum (in about $15 \%$ of cases) [8]. The risk factors include first pregnancy (primigravida), excessive maternal weight gain, and multiple pregnancies [29, 30].

\subsubsection{Pathophysiology and Clinical Characteristics}

Stretching of the skin on the abdomen at the third trimester of pregnancy or over multiple pregnancies may activate dermal nerve endings, leading to pruritus [26, 31]; however, the exact pathogenesis of PEP remains elusive. Another theory suggests that damage to the collagen fibers may induce an allergic-type response, contributing to the development of PEP lesions.

The clinical presentation includes polymorphic skin lesions: highly pruritic urticarial papules that coalesce into plaques, small vesicles $1-2 \mathrm{~mm}$ in size (no bullae), widespread non-urticated erythema, and targetoid and eczematous lesions generally sparing the periumbilical region $[8,26,32]$. The lesions might change in time with the development of the disease [33]. PEP usually starts in the abdominal region, within striae distensae, if they are present. The disease spreads to other body sites such as the thighs, buttocks, and the rest of the trunk; involvement of distal extremities is very rare [34].

\subsubsection{Diagnostic Workup}

There are no characteristic histological or immunofluorescence findings, and the diagnosis is purely based on the clinical presentation of the disease. As pre-bullous PG is clinically almost indistinguishable from PEP, prolonged follow-up of patients with PEP is recommended. If clinical uncertainty regarding the diagnosis exists, DIF to rule out a pre-bullous PG should be performed.

\subsubsection{Treatment}

Since the disease resolves spontaneously within 4-6 weeks (independently of delivery), the treatment is symptomatic [29] (Fig. 1). Emollients, antihistamines, and topical glucocorticosteroids are considered first-line treatments. If the disease is extensive and pruritus does not resolve, systemic prednisolone may be considered.

\subsubsection{Prognosis and Fetal Risks}

PEP is a self-limiting disorder that does not affect the prognosis for the fetus or the pregnant patient. Recurrence is rare as it usually occurs only in first pregnancies [29].

\subsection{Pemphigoid Gestationis}

\subsubsection{Definition and Epidemiology}

PG, also known as herpes gestationis, is a rare self-limited pregnancy-associated bullous autoimmune disease. Although it usually occurs in the late third trimester, it may develop at any time during pregnancy or in the immediate postpartum [8, 35-39]. The first cases of PG complicating egg donation pregnancy have recently been reported [40, $41]$. Beyond pregnancy, it can very rarely occur in association with trophoblastic tumors (choriocarcinoma and hydatidiform mole) [42-48]. The incidence is approximately 1:2000-1:60,000 pregnancies, depending on the prevalence of the human leukocyte antigen (HLA) haplotypes DR3 and DR4 $[49,50]$. Relapse of the disease is common (in about $30-50 \%$ of patients) in further pregnancies, often occurring at an earlier stage and in a more severe form [26, 37, 38, $51,52]$.

\subsubsection{Pathophysiology and Clinical Characteristics}

Despite the rarity of the disease, the pathogenesis is wellestablished and is considered to be similar to that of bullous pemphigoid with autoantibodies (immunoglobulin G1 [IgG1] subclass) directed against bullous pemphigoid antigen 180 (BP180) [53, 54]. BP180 is found both in the basement membrane zone of the skin and in placental tissue and fetal membranes. Of interest, the primary site of autoimmunity seems to be the placenta rather than the skin. Proteins presented in the placenta are recognized as foreign, which leads to the production of anti-placental IgG antibodies cross-reacting with BP180-2 proteins in the skin. Binding of these antibodies to the BP180 and BP230 in the hemidesmosomes of the dermoepidermal junction triggers an autoimmune response: complement activation with subsequent deposition of immunocomplexes, consecutive chemoattraction of eosinophil granulocytes, and-finally-degranulation, all of which result in disruption of the basement membrane and blister formation [54].

Clinically, the patient initially presents with severe pruritus and subsequent polymorphic inflammatory skin lesions. At first, erythematous urticarial papules and plaques develop on the abdomen, characteristically involving the periumbilical region, with later spread to other parts of the abdomen and extremities. The disease may involve the entire skin area and mucosal membranes $[8,36,37,52]$. Later on, lesions 
progress to tense blisters similar to those seen in bullous pemphigoid [36].

\subsubsection{Diagnostic Workup}

DIF of perilesional skin together with clinical findings remains the gold standard for establishing the diagnosis of PG. DIF shows linear C3 and/or IgG deposits along the dermo-epidermal junction $[36,55]$. Histology is not specific and is usually carried out to exclude other potential dermatoses. For biopsy, both lidocaine and epinephrine are considered safe for local anesthesia [16]. If the patient wants to avoid a skin biopsy, detection of circulating autoantibodies can be achieved using complement-binding tests, such as indirect immunofluorescence or enzyme-linked immunosorbent assay (ELISA). ELISA typically reveals circulating IgG antibodies against BP180 with 94-98\% specificity and $86-97 \%$ sensitivity. ELISA is also useful to monitor the activity of the disease [56-58].

\subsubsection{Treatment}

The natural course of PG includes remissions and exacerbations during pregnancy, with characteristic flares during delivery or immediately postpartum resolving spontaneously within 4 weeks $[9,59]$. The disease may also flare after abortion. Rarely, the disease recurs during menstruation or with use of oral contraceptives [60]. As the disease may cause fetal complications (such as preterm labor and intrauterine growth retardation), patients should undergo strict dermatological and gynecological follow-up during the entire pregnancy.

Treatment of PG mainly focuses on reducing pruritus and preventing the formation of new blisters. The treatment of choice is high-potency topical glucocorticosteroids and antihistamines. In patients with blistering disorders, nonfluorinated topical glucocorticosteroids are preferable, as the disrupted skin barrier may induce systemic absorption, and non-fluorinated topical glucocorticosteroids are known to cause fewer side effects $[61,62]$. If topical glucocorticosteroids are contraindicated or the patient refuses treatment, therapy with calcineurin inhibitors may be introduced on small areas with caution (no more than $5 \mathrm{~g} /$ day for 2-3 weeks) $[16,63]$. As a second-line treatment, short courses of prednisolone up to $0.5 \mathrm{mg} / \mathrm{kg} /$ day (preferably $<20 \mathrm{mg} /$ day) should be introduced [16,64]. If response to treatment is adequate (no new blister formation for 2 weeks), topical and systemic glucocorticosteroids should be slowly tapered to prevent fetus-related side effects $[65,66]$. If PG remains refractory to treatment, or prolonged courses of steroids are required, other agents such as intravenous immunoglobulins, dapsone, and azathioprine $<2 \mathrm{mg} / \mathrm{kg} /$ day should be considered as steroid-sparing agents [65]. Intravenous immunoglobulins (FDA pregnancy category C) have a good safety profile for the patient and fetus and should be used either in monotherapy or as adjuvant treatment [66-74]. Dapsone (FDA pregnancy category C) is also considered safe during gestation. Glucose-6-phosphate dehydrogenase levels should be measured before initiation. Close blood monitoring with a special emphasis on methemoglobin because of the risk of maternal or neonatal anemia is of utmost significance [64]. Vitamin E 800 U/daily and C 1 g/ daily should be supplemented to decrease the risk of potential side effects [75]. More information about the use of azathioprine and its safety profile may be found in Sect. 5.2.4.

Rituximab administered before conception may help to prevent the recurrence of $\mathrm{PG}$ in subsequent pregnancies, but rituximab has a long half-life, and patients are advised to avoid pregnancy 12 months after the last infusion [76, 77]. After delivery or abortion, the full spectrum of immunosuppressive agents should be considered.

\subsubsection{Prognosis and Fetal Risks}

Fetal prognosis is relatively good. The risks include preterm labor and intrauterine growth retardation and are most probably linked to the severity of the disease itself rather than the treatment [78]. PG is associated with an increased risk of other autoimmune disorders in the pregnant patient, especially Graves disease, which may be explained by the presence of HLA-DR3 and DR4 [36]. The disease tends to recur in subsequent pregnancies.

\subsection{Intrahepatic Cholestasis in Pregnancy}

\subsubsection{Definition and Epidemiology}

ICP is a liver disorder unique to pregnancy and has a reported incidence of $0.3-5.6 \%$ and ethnic, geographic, and seasonal variations [2, 79-85] (clinical case 2). A striking geographic variation is noted, with an incidence as high as $28 \%$ especially in patients with overt Araucanian Indian descent [86]. Mutations of $A B C B 4$ (MDR3) involved in the biliary secretion of phospholipids have been studied in ICP and may play an important role, at least in some patients [87]. Diseases associated with ICP include gallstones [88, 89], hepatitis C infection [90, 91], preeclampsia, and gestational diabetes [92-94]. ICP is characterized by an inability to excrete bile salts from the liver, which increases serum bile acid concentration, causing pruritus (possibly because of the increased availability of brain opiate receptors [95]) and negatively influences the fetal prognosis. It is a reversible cholestasis that occurs in the second and third trimesters of pregnancy ( $>30$ th week). Earlier onset has been sporadically reported $[96,97]$. 


\section{Clinical Case 2}

Clinical presentation A 40-year-old woman presented in the 27th week of gestation with generalized pruritus without primary skin lesions, involving palms and soles, which started in the second trimester. This condition was very burdensome for the patient and was causing severe sleep impairment. The patient was initially given topical steroids, anti-scabies treatment, and cetirizine $10 \mathrm{mg}$ once daily in an attempt to relieve her symptoms, without therapeutic effect.

Workup Clinical examination revealed multiple disseminated telangiectasia all over the body, especially at the palms and soles, most probably incidental to the pruritus and due to hormonal changes in pregnancy. Additionally, the whites of the eyes showed a yellowish coloration. The patient had negative personal and family history of atopic conditions and other dermatological disorders. The serum bile acid level was $12.2 \mu \mathrm{mol} / \mathrm{l}$ (reference value $0-6 \mu \mathrm{mol} / \mathrm{l}$ ), with only marginally elevated aspartate aminotransferase (37 U/l; reference value 10-35 U/1), serum amylase (107 U/l; reference value $28-100 \mathrm{U} / \mathrm{l})$, and triglycerides $(236 \mathrm{mg} / \mathrm{dl}$; reference value $<150$ $\mathrm{mg} / \mathrm{dl})$.

Treatment and course Based on the clinical picture and laboratory findings, the diagnosis of intrahepatic cholestasis in pregnancy was made. Therapy with ursodeoxycholic acid $500 \mathrm{mg}$ twice daily and loratadine $10 \mathrm{mg}$ twice daily was initiated. Emollients with polidocanol, urea, and menthol were recommended. The patient was lost to follow-up.

\subsubsection{Pathophysiology and Clinical Characteristics}

Potential etiopathogenetic factors include genetic (altered expression of hepatobiliary transport proteins), hormonal (especially estrogen levels), and environmental factors such as seasonal variability and diet [87, 98]. Recent studies have explored the role of alterations in gut microbiota and long-term therapy with vaginal progesterone preparations as potential risk factors for ICP $[99,100]$.

Clinical triad characteristics for this disease include severe pruritus, jaundice starting 2-4 weeks after the onset of pruritus, and elevated bile acids [82]. The disease is characterized by elevated serum bile acids in maternal blood ( $>10 \mu \mathrm{mol} / \mathrm{l}$ ) and abnormal liver function results (mainly serum transaminases) [101]. Although the disease is historically linked to jaundice [102], more recent data have indicated that yellowish or greenish pigmentation of the skin and whites of the eyes is reported in only about $10 \%$ of patients [103]. Pruritus classically begins on the palms and soles but may become generalized. Patients present without skin alterations apart from secondary scratch lesions. Pruritus might worsen with the development of the pregnancy. Other symptoms include steatorrhea and dark urine.

\subsubsection{Diagnostic Workup}

Diagnostic workup should focus on the exclusion of other clinical entities included in the differential diagnosis of cholestasis and hepatic disease and on increased serum bile acid levels $>10 \mu \mathrm{mol} / \mathrm{l}$. Mild increases in liver transaminase levels, including aspartate aminotransferase and alanine aminotransferase, can also be observed. Ultrasound examination of the abdomen and serologic tests may be helpful to exclude other potential underlying causes. Diagnosis is based on the characteristic symptom of pruritus starting at the palms and soles without primary skin lesions, together with increased total serum bile acid levels.

\subsubsection{Treatment}

ICP usually resolves spontaneously within 6 weeks after delivery [104]. The primary goal in the management of ICP is to reduce serum bile acid levels, which is proven to reduce pruritus, prolong pregnancy, and decrease fetal risks. The first-line treatment is the administration of ursodeoxycholic acid (UDCA) $15 \mathrm{mg} / \mathrm{kg} / \mathrm{day}$ (not assigned an FDA pregnancy category) [105]. Although the PITCH study published in 2019 in The Lancet [106] suggested that UDCA may not be effective in preventing stillbirth, the newly published guidelines (2021) [107] highlighted weaknesses of the PITCH study (the administered dose of UDCA was not taken into consideration) and advocated for the use of UDCA in this group of patients. The role of the synergistic effect of rifampicin 300-1200 mg (FDA pregnancy category C) on bile acid clearance in severe ICP (bile acids $>100 \mu \mathrm{mol} / \mathrm{l}$ ) is still being discussed [108-111] and should be considered when there is no improvement with UDCA alone. Early-term induction should be discussed with patients, especially after gestation week 37 (or sooner with documented pulmonary maturity) and if bile acid concentrations are $>100 \mathrm{mmol} / \mathrm{l}$ [79].

\subsubsection{Prognosis and Fetal Risks}

ICP has been associated with increased rates of fetal complications, perinatal mortality rates, stillbirths, low birth weight, preterm birth, and fetal distress during labor [102, 112-115].

\section{Other Pruritic Conditions in Pregnancy}

Pruritic dermatoses that are known to flare during pregnancy include psoriasis (especially pustular psoriasis), atopic dermatitis, dyshidrotic eczema, dermatomyositis, urticaria, mastocytosis, and lichen planus [116, 117]. Infections and infestations such as scabies and bacterial, mycological, and viral infections (including pityriasis rosea, HIV/AIDS, Zika, and coronavirus disease 2019 [COVID-19]) should also be part of the differential diagnosis of pruritus in the pregnant patient [118-120]. It is important for clinicians to keep these conditions in mind, as their management may 
differ in pregnant patients. Some $20 \%$ of pregnancies are complicated with pruritus due to skin diseases, such as vulvar lichen sclerosus or irritant contact dermatitis, coinciding with pregnancy $[8,121,122]$.

Pruritus may also result from physiological changes during pregnancy. Pregnancy alters glucose metabolism and predisposes patients to gestational diabetes. Although the exact pathogenesis of pruritus in diabetes is not known, it is likely that altered insulin levels in short-lasting diabetes mellitus cause skin dryness and subsequently pruritus [123-126]. According to a recent study, pruritus due to diabetes may complicate $0.68 \%$ of all pregnancies [2]. Abdominal stretching and leg edema together with increased sweat gland activity might also predispose to skin xerosis. Other possible causes of $\mathrm{CP}$ of non-lesional skin in pregnancy include hypothyroidism (1.02\%) and chronic hepatitis B and $\mathrm{C}$ virus infection $(0.34 \%)$ [2, 127].

Clinicians should be aware that pruritus without skin lesions may occur before the presentation of other symptoms, which is typical in the course of PG and ICP. Therefore, careful examination and prolonged follow-up should be considered in all pregnant patients with pruritus without skin lesions to avoid missing diseases that may impair fetal health.

\section{Therapeutic Considerations}

Treating pruritus in pregnancy remains a challenge requiring prudent consideration of the potential benefits to the pregnant patient as well as the possible negative effects on the fetus. If possible, specific topical and systemic treatments for the underlying etiology should be initiated (Table 2). Additionally, general pruritus-relieving measures, which include avoidance of factors that foster dryness of the skin, use of mild detergents, and sufficient emollient therapy should be taken into consideration [15] (Fig. 2).

\subsection{Topical Treatment}

\subsubsection{Glucocorticosteroids}

Topical glucocorticosteroids are usually considered as firstline treatment of $\mathrm{CP}$ if inflammatory skin lesions are present. According to a Cochrane review update [128], there are no causal associations between maternal exposure to low- or moderate-potency topical glucocorticosteroids (i.e., methylprednisolone aceponate) (Table 3 ) and pregnancy outcomes, including mode of delivery, congenital abnormalities, preterm delivery, and fetal death. However, caution is warranted with excessive use of potent or very potent topical glucocorticosteroids because a risk of low birth weight seems to correlate with the quantity of topical corticosteroid exposure (total dosage $>300 \mathrm{~g}$ during the entire pregnancy) [129].

\subsubsection{Calcineurin Inhibitors}

If usage of topical steroids is contraindicated or the patient refuses treatment, topical calcineurin inhibitors may be introduced with caution. They should be applied only on small areas and with no more than $5 \mathrm{~g}$ /day for 2-3 weeks or when needed $[16,63]$.

\subsection{Systemic Treatment}

\subsubsection{Antihistamine Drugs}

Several studies have evaluated the safety of antihistamines during pregnancy [130-134]. The first-generation $\mathrm{H}_{1}$ antihistamine (sedative) chlorpheniramine (4 mg every 4-6 h; FDA pregnancy category B) can be administrated in early pregnancy as first-line therapy. It is widely available and inexpensive and can be useful on an as-needed basis and/or before bed. Second-generation antihistamines (nonsedative) have a less sedating effect and fewer cholinergic side effects than first-generation agents. They should be introduced from the second semester on as they may incur a higher risk of malformations (neural tube defects, hypoplastic left heart syndrome, and tetralogy of Fallot) [134] when used in early pregnancy. Loratadine $10 \mathrm{mg}$ once daily and cetirizine $10 \mathrm{mg}$ once daily are considered second-generation antihistamines of choice in pregnancy [131, 133]. Data regarding the use of levocetirizine (FDA pregnancy category B) and fexofenadine (FDA pregnancy category C) are also reassuring $[135,136]$.

\subsubsection{Phototherapy}

Narrowband UVB is considered safe in pregnancy and is recommended as a second-line treatment, especially in early pregnancy, when other medications are contraindicated [16]. Although patients who have been exposed to high levels of UVB radiation do not have an increased risk of abnormal delivery outcomes, it is worth remembering that there is a paucity of studies regarding ultraviolet A (UVA) or UVB light therapy and pregnancy-related complications or long-term effects on the fetus. The use of UVB therapy was linked with low levels of serum folate, and folate supplementation $(0.8 \mathrm{mg} /$ day) should be recommended to reduce the risk of neural tube defects [137-139]. Patients are also at risk of developing melasma after UV exposure [140], so facial covering is advised.

\subsubsection{Glucocorticosteroids}

For severe cases of recalcitrant pruritus, short-term systemic treatment with glucocorticosteroids may be considered. Prednisolone $0.5-2 \mathrm{mg} / \mathrm{kg} / \mathrm{day}$ is the corticosteroid of choice in pregnancy. Oral steroids should be used with caution in the first trimester of pregnancy because of the unclear association 


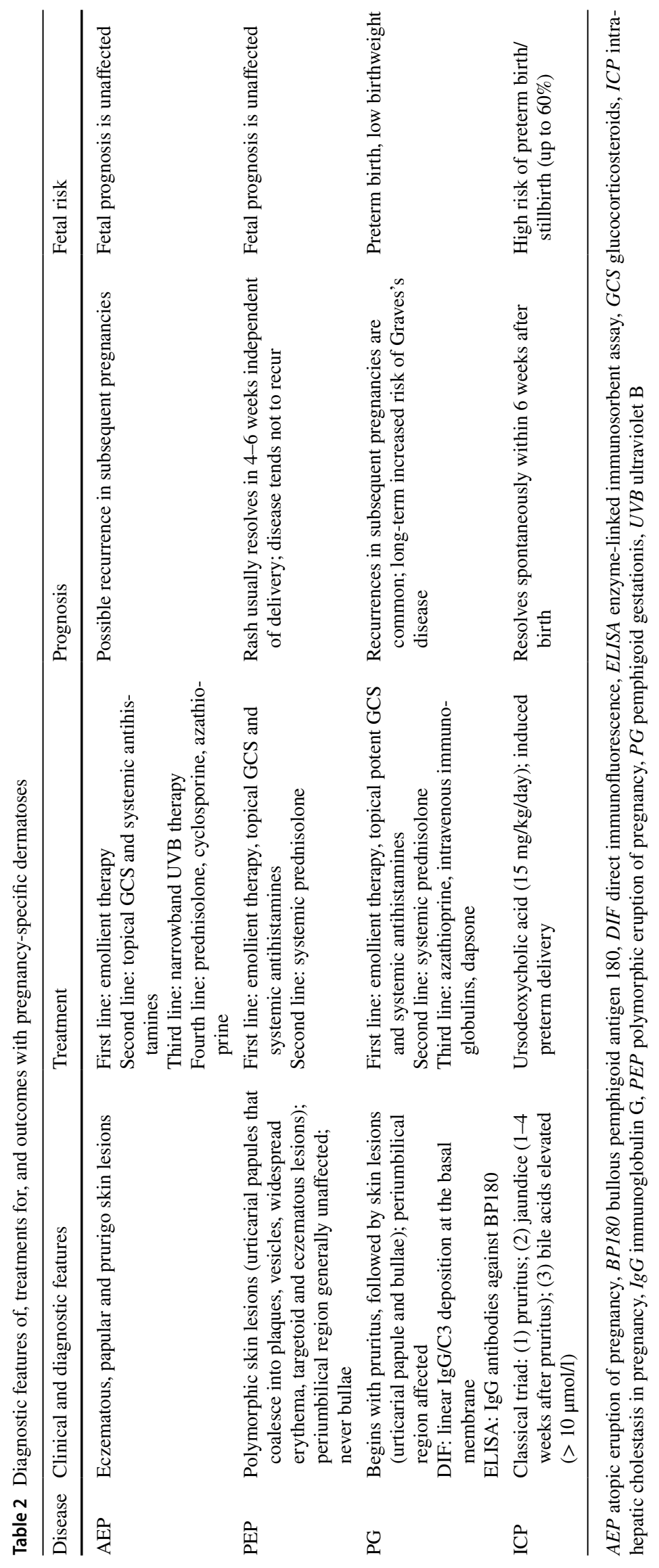


Table 3 Low to medium potency (groups 4-7) topical corticosteroid preparations (classified according to the US system) [154, 155]

\begin{tabular}{|c|c|}
\hline Potency group & Corticosteroid \\
\hline \multirow[t]{8}{*}{ Medium potency (group 4) } & Betamethasone dipropionate (spray $0.05 \%$ ) \\
\hline & Clocortolone pivalate (cream $0.1 \%$ ) \\
\hline & Fluocinolone acetonide (ointment $0.025 \%$ ) \\
\hline & Flurandrenolide (ointment $0.05 \%$ ) \\
\hline & Fluticasone propionate (cream $0.05 \%$ ) \\
\hline & Hydrocortisone valerate (ointment $0.2 \%$ ) \\
\hline & Mometasone furoate (cream, lotion, solution $0.1 \%$ ) \\
\hline & $\begin{array}{l}\text { Triamcinolone acetonide (cream } 0.1 \% \text {; ointment } 0.05 \% \text { or } 0.1 \% \text {; } \\
\text { aerosol } 0.2 \mathrm{mg} / 2 \text { second spray, dental paste } 0.1 \% \text { ) }\end{array}$ \\
\hline \multirow[t]{11}{*}{ Lower-mid potency (group 5) } & Betamethasone dipropionate (lotion $0.05 \%$ ) \\
\hline & Betamethasone valerate (cream $0.1 \%$ ) \\
\hline & Desonide (ointment, gel $0.05 \%$ ) \\
\hline & Fluocinolone acetonide (cream $0.025 \%$ ) \\
\hline & Flurandrenolide (cream, lotion $0.05 \%$ ) \\
\hline & Fluticasone propionate (lotion $0.05 \%$ ) \\
\hline & Hydrocortisone butyrate (cream, lotion, ointment, solution $0.1 \%$ ) \\
\hline & Hydrocortisone probutate (cream $0.1 \%$ ) \\
\hline & Hydrocortisone valerate (cream $0.2 \%$ ) \\
\hline & Prednicarbate (cream, ointment $0.1 \%$ ) \\
\hline & Triamcinolone acetonide (lotion $0.1 \%$, ointment $0.025 \%$ ) \\
\hline \multirow[t]{5}{*}{ Low potency (group 6) } & Alclometasone dipropionate (cream, ointment $0.05 \%$ ) \\
\hline & Betamethasone valerate (lotion $0.1 \%$ ) \\
\hline & Desonide (cream, lotion, foam $0.05 \%$ ) \\
\hline & Fluocinolone acetonide (cream, lotion, oil $0.01 \%$ ) \\
\hline & Triamcinolone acetonide (cream, lotion $0.025 \%$ ) \\
\hline Least potent (group 7) & Hydrocortisone acetate (cream $1 \%, 2.5 \%$, lotion $2 \%$ ) \\
\hline
\end{tabular}

with orofacial clefts [141, 142]. Although some studies suggested that the use of glucocorticosteroids in pregnancy might be associated with lower birth body weight [143], single treatments of medium to high doses of glucocorticosteroids in the third trimester did not affect body size or cardiovascular risk factors of the offspring in long-term follow-up [144]. During pregnancy, long-term use of glucocorticosteroids may also increase the risk of gestational diabetes, preeclampsia, and even membrane rupture and preterm delivery.

\subsubsection{Other Immunosuppressive Agents}

In cases not responding to phototherapy and requiring prolonged courses of systemic glucocorticosteroids, steroid-sparing agents, such as cyclosporine (FDA pregnancy category C) or azathioprine (FDA pregnancy category D) [17] should be considered. When initiating cyclosporine A, the minimal possible dose should be used, and maternal blood pressure and renal function should be monitored closely. Data on the use of cyclosporine in dermatological conditions in pregnancy are sparse and are primarily derived from organ transplant recipients. The teratogenic risk among the offspring appears to be low, even though lower body weight in infants and premature labor have been reported. However, all these events might be associated with the patients' medical conditions rather than with the drug itself [145, 146]. Azathioprine is considered relatively safe in pregnancy and has not been linked with teratogenicity [145, 147]. Data on the usage of azathioprine in pregnancy come mostly from studies of transplant recipients and patients with Crohn disease. In these groups, higher rates of pregnancy complications (low birth weight, prematurity, and jaundice) have been reported [148]. Analysis of the Swedish Medical Birth Register has indicated a possibility of a moderately increased risk of congenital malformations, specifically ventricular/atrial septal defects, and a higher risk of growth restriction and preterm delivery in infants exposed to azathioprine during early pregnancy [149].

\subsubsection{Biologics and Small Molecules}

Monoclonal antibodies targeting components of the immune system, such as cytokines or chemokines, are included in biological therapy. They were developed to treat primary autoimmune disorders, but a growing number of clinical 
studies are investigating biologics and small molecules as new treatments for pruritic dermatoses. They are considered a treatment option in moderate to severe disease phenotypes when conventional treatment is not tolerated or efficiency is limited. Unfortunately, data regarding the safety profile in pregnancy remain limited.

The humanized recombinant monoclonal antibody omalizumab (FDA pregnancy category B) binds specifically to the $\mathrm{C} \varepsilon 3$ domain of the IgE heavy chain and is used in the treatment of chronic spontaneous urticaria [150]. It is considered a safe and effective therapeutic option in pregnant patients refractory to antihistamines [151-153].

The anti-IL-4R- $\alpha$ antibody dupilumab is considered an effective option in the treatment of refractory atopic dermatitis. To date, only two case reports of treatment with dupilumab in pregnancy with good fetus and pregnancy outcomes have been published [20,21]. We recommend postponing the use of dupilumab in pregnancy until more data regarding the safety profile are available.

To date, data regarding safety and efficacy are insufficient to recommend small molecules (such as neurokinin 1 and Janus kinase inhibitors) in the treatment of $\mathrm{CP}$ in pregnant patients.

\section{Conclusion}

In pregnancy, pruritus is the main dermatological symptom and should never be neglected. Patients presenting with pruritus need an exact workup to establish a proper diagnosis, which is not only essential for the wellbeing of the expectant patient but also to prevent negative outcomes for the fetus. Pruritus is the main symptom of pregnancy-specific dermatological diseases such as PEP, PG, AEP, and ICP but may also coincide by chance with other diseases or even physiological changes in pregnancy. In the algorithmic approach, the first step is to rule out other possible causes of pruritus; in the second step, the four specific dermatoses of pregnancy need to be differentiated [26]. Careful medical history with an emphasis on the location and temporal course of the pruritus often reveals important clues that, together with laboratory findings, may facilitate diagnosis and efficacious treatment. Treatment of pruritus in pregnancy requires prudent consideration of the benefits and risks of the available therapeutic regimens for the patient and fetus. All specialists involved (dermatologist, gynecologist, general practitioner, midwife) should cooperate closely to improve the management of pruritus in pregnancy.

\section{Declarations}

Funding No sources of funding were used to conduct this study or prepare this manuscript.
Conflict of interest AAS has no conflicts of interest that are directly relevant to the content of this article. MPP has served as an investigator for Trevi Therapeutics, is a consultant for Galderma, and has received speaker honoraria/travel fees from AbbVie, Beiersdorf, Eli Lilly, Galderma, Menlo Therapeutics, Novartis, P. G. Unna Academy, and Trevi Therapeutics. CZ has served as an investigator in clinical trials for Novartis, Janssen, Pfizer, UCB, Lilly, AbbVie, Boehringer Ingelheim, Sanofi, Regeneron, Leo, and Galderma; has received speaker honoraria from Dermasence, Beiersdorf, and Leo; and has received author honoraria from AbbVie. SS has served as an investigator in clinical trials for Dermasence, Galderma, Kiniksa, Menlo Therapeutics, Novartis, Sanofi, Trevi Therapeutics, and Vanda Therapeutics and as a consultant and/or member of an advisory board for AbbVie, Almirall, Beiersdorf, Bellus, Bionorica, Cara Therapeutics, Celgene, Clexio, DS Biopharma, Escient, Galderma, Leo, Lilly, Kiniksa, Menlo, Novartis, Pfizer, Sanofi, Trevi Therapeutics, and Vifor

Ethics approval Not applicable.

Consent for participation/publication Consent was obtained for publication of patient photographs included in this manuscript.

Availability of data and material Not applicable.

Code availability Not applicable.

Author contributions All authors contributed significantly to the concept and planning, drafting, and revision of the manuscript. All authors approved the final submitted version of the manuscript.

Open Access This article is licensed under a Creative Commons Attribution-NonCommercial 4.0 International License, which permits any non-commercial use, sharing, adaptation, distribution and reproduction in any medium or format, as long as you give appropriate credit to the original author(s) and the source, provide a link to the Creative Commons licence, and indicate if changes were made. The images or other third party material in this article are included in the article's Creative Commons licence, unless indicated otherwise in a credit line to the material. If material is not included in the article's Creative Commons licence and your intended use is not permitted by statutory regulation or exceeds the permitted use, you will need to obtain permission directly from the copyright holder. To view a copy of this licence, visit http://creativecommons.org/licenses/by-nc/4.0/.

\section{References}

1. Wong R, Ellis C. Physiologic skin changes in pregnancy. J Am Acad Dermatol. 1984;10:929-40. https://doi.org/10.1016/S01909622(84)80305-9.

2. Szczęch J, Wiatrowski A, Hirnle L, Reich A. Prevalence and relevance of pruritus in pregnancy. Biomed Res Int. 2017. https:// doi.org/10.1155/2017/4238139.

3. Weisshaar E, Witteler R, Diepgen TL, Luger TA, Ständer S. Pruritus in pregnancy. A common diagnostic and therapeutic challenge. Hautarzt. 2005;56:48-57. https://doi.org/10.1007/ s00105-004-0833-1.

4. Dinatale M. The pregnancy and lactation labeling rule (PLLR) Division of Pediatric and Maternal Health FDA/CDER/OND/ ODEIV Pediatric Advisory Committee Meeting. 2016.

5. Elling SV, Powell FC. Physiological changes in the skin during pregnancy. Clin Dermatol. 1997;15:35-43. https://doi.org/10. 1016/S0738-081X(96)00108-3. 
6. Kannambal K, Tharini GK. A screening study on dermatoses in pregnancy. J Clin Diagn Res. 2017;11:WC01-5. https://doi.org/ 10.7860/JCDR/2017/27207.9907.

7. Hajhashemi M, Rafieian M, Rouhi Boroujeni HA, Miraj S, Memarian S, Keivani A, et al. The effect of Aloe vera gel and sweet almond oil on striae gravidarum in nulliparous women. $\mathbf{J}$ Matern Neonatal Med. 2018;31:1703-8. https://doi.org/10.1080/ 14767058.2017.1325865.

8. Ambros-Rudolph C, Müllegger R, Vaughan-Jones S, Kerl H, Black $M$. The specific dermatoses of pregnancy revisited and reclassified: results of a retrospective two-center study on 505 pregnant patients. J Am Acad Dermatol. 2006;54:395-404. https://doi.org/10.1016/J.JAAD.2005.12.012.

9. Vaughan Jones SA, Hern S, Nelson-Piercy C, Seed PT, Black MM. A prospective study of 200 women with dermatoses of pregnancy correlating clinical findings with hormonal and immunopathological profiles. Br J Dermatol. 1999;141:71-81. https:// doi.org/10.1046/j.1365-2133.1999.02923.x.

10. Akdis M, Trautmann A, Klunker S, Blaser K, Akdis CA. T cells and effector mechanisms in atopic dermatitis. In: New trends allergy V. Berlin: Springer; 2002. p. 113-20. https://doi.org/10. 1007/978-3-642-55994-5_16.

11. Ravelli FN, Goldust M, Kroumpouzos G (2020) Assessment of prurigo of pregnancy in patients without atopicbackground. Int J Womens Dermatol 6:384-389.

12. Ambros-Rudolph CM, Sticherling M. Specific dermatoses of pregnancy. Hautarzt. 2017;68:87-94. https://doi.org/10.1007/ S00105-016-3922-Z.

13. Koutroulis I, Papoutsis J, Kroumpouzos G. Atopic dermatitis in pregnancy: current status and challenges. Obstet Gynecol Surv. 2011;66:654-63. https://doi.org/10.1097/OGX.0b013e3182 $3 \mathrm{a} 0908$.

14. Treudler R. Allergic diseases in pregnancy. Overview of diagnosis and therapy. Hautarzt. 2010;61:1027-33. https://doi.org/10. 1007/S00105-010-2008-6.

15. Weisshaar E, Szepietowski JC, Dalgard F, Garcovich S, Gieler U, Gimenez-Arnau A et al (2019) European S2k guideline on chronic pruritus. Acta Derm Venereol 99:469-506.

16. Murase JE, Heller MM, Butler DC. Safety of dermatologic medications in pregnancy and lactation: Part I. Pregnancy. J Am Acad Dermatol. 2014;70:401.e1-401.e14. https://doi.org/10.1016/j. jaad.2013.09.010.

17. Vestergaard C, Wollenberg A, Barbarot S, Christen-Zaech S, Deleuran M, Spuls P, et al. European task force on atopic dermatitis position paper: treatment of parental atopic dermatitis during preconception, pregnancy and lactation period. J Eur Acad Dermatol Venereol. 2019;33:1644-59. https://doi.org/10.1111/ JDV.15709.

18. Tsianakas A, Ständer S. Dupilumab: a milestone in the treatment of atopic dermatitis. Lancet. 2016;387:4-5. https://doi.org/10. 1016/S0140-6736(15)00389-X.

19. Andrews A-L, Holloway JW, Holgate ST, Davies DE. IL-4 receptor $\alpha$ is an important modulator of IL-4 and IL-13 receptor binding: implications for the development of therapeutic targets. $\mathbf{J}$ Immunol. 2006;176:7456-61. https://doi.org/10.4049/jimmunol. 176.12 .7456

20. Lobo Y, Lee RC, Spelman L. Atopic dermatitis treated safely with dupilumab during pregnancy: a case report and review of the literature. Case Rep Dermatol. 2021;13:248-56. https://doi. org/10.1159/000515246.

21. Mian M, Dunlap R, Simpson E. Dupilumab for the treatment of severe atopic dermatitis in a pregnant patient: a case report. JAAD Case Rep. 2020;6:1051-2. https://doi.org/10.1016/j.jdcr. 2020.08.001.
22. Kroumpouzos G, Cohen LM. Specific dermatoses of pregnancy: an evidence-based systematic review. Am J Obstet Gynecol. 2003;188:1083-92. https://doi.org/10.1067/mob.2003.129.

23. Kroumpouzos G, Cohen LM. Dermatoses of pregnancy. J Am Acad Dermatol. 2001;45:1-22. https://doi.org/10.1067/mjd. 2001.114595.

24. Moore MM, Rifas-Shiman SL, Rich-Edwards JW, Kleinman KP, Camargo CA, Gold DR, et al. Perinatal predictors of atopic dermatitis occurring in the first six months of life. Pediatrics. 2004;113:468-74. https://doi.org/10.1542/peds.113.3.468.

25. Dominguez-Serrano AJ, Quiroga-Garza A, Jacobo-Baca G, De La Fuente-Villarreal D, Gonzalez-Ramirez RA, Vazquez-Barragan MA, et al. Polymorphic eruption of pregnancy in Mexico. Int J Dermatol. 2019;58:259-62. https://doi.org/10.1111/ijd.14337.

26. Ambros-Rudolph CM. Dermatoses of pregnancy - clues to diagnosis, fetal risk and therapy. Ann Dermatol. 2011;23:265-75. https://doi.org/10.5021/ad.2011.23.3.265.

27. Ghazeeri G, Kibbi AG, Abbas O. Pruritic urticarial papules and plaques of pregnancy: epidemiological, clinical, and histopathological study of 18 cases from Lebanon. Int J Dermatol. 2012;51:1047-53. https://doi.org/10.1111/j.1365-4632.2011. 05203.x.

28. Alcalay J, Ingber A, David M, Hazaz B, Sandbank M. Pruritic urticarial papules and plaques of pregnancy. A review of 21 cases. J Reprod Med Obstet Gynecol. 1987;32:315-6.

29. Rudolph CM, Al-Fares S, Vaughan-Jones SA, Müllegger RR, Kerl H, Black MM. Polymorphic eruption of pregnancy: clinicopathology and potential trigger factors in 181 patients. Br J Dermatol. 2006;154:54-60. https://doi.org/10.1111/j.1365-2133. 2005.06856.x.

30. Regnier S, Fermand V, Levy P, Uzan S, Aractingi S. A case-control study of polymorphic eruption of pregnancy. J Am Acad Dermatol. 2008;58:63-7. https://doi.org/10.1016/j.jaad.2007.08.015.

31. Petropoulou H, Georgala S, Katsambas AD. Polymorphic eruption of pregnancy. Int J Dermatol. 2006;45:642-8. https://doi. org/10.1111/J.1365-4632.2006.02715.X.

32. Bohdanowicz M, Ghazarian D, Rosen CF. Targetoid form of polymorphic eruption of pregnancy: a case report. SAGE Open Med Case Rep. 2019;7:2050313X1988284. https://doi.org/10. 1177/2050313x19882841.

33. Roth M-M. Pregnancy dermatoses: diagnosis, management, and controversies. Am J Clin Dermatol. 2011;12:25-42.

34. Özcan D, Özçakmak B, Aydoğan FÇ. Polymorphic eruption of pregnancy with palmoplantar involvement that developed after delivery. J Obstet Gynaecol Res. 2011;37:1158-61. https://doi. org/10.1111/j.1447-0756.2010.01492.x.

35. Radia C, Salim G, Kawtar I, Fatima Zahra M, Taoufiq H. Pemphigoid gestationis: a Moroccan study. Our Dermatol Online. 2017;8(2):128-32. https://doi.org/10.7241/ourd.20172.36.

36. Jenkins RE, Hern S, Black MM. Clinical features and management of 87 patients with pemphigoid gestationis. Clin Exp Dermatol. 1999;24:255-9. https://doi.org/10.1046/j.1365-2230. 1999.00472.x.

37. Al-Saif F, Elisa A, Al-Homidy A, Al-Ageel A, Al-Mubarak M. Retrospective analysis of pemphigoid gestationis in 32 Saudi patients - clinicopathological features and a literature review. J Reprod Immunol. 2016;116:42-5. https://doi.org/10.1016/j.jri. 2016.04.286.

38. Hallaji Z, Mortazavi H, Ashtari S, Nikoo A, Abdollahi M, Nasimi M. Pemphigoid gestationis: clinical and histologic features of twenty-three patients. Int J Womens Dermatol. 2017;3:86. https:// doi.org/10.1016/J.IJWD.2016.11.004.

39. Mokni M, Fourati M, Karoui I, El Euch D, Cherif F, Ben Tekaya N, et al. Pregnancy pemphigoid: study of 20 cases. Ann Dermatol Venereol. 2004;131:953-6. https://doi.org/10.1016/S01519638(04)93804-5. 
40. Guerra L, Mazzanti C, Calabresi V, De Luca N, Zambruno G, Di Zenzo G. Pemphigoid gestationis complicating an egg donation pregnancy. Acta Derm Venereol. 2016;96:695-6. https://doi.org/ 10.2340/00015555-2303.

41. Oms E, Tronnier M. Pemphigoid gestationis after egg donation: a case report. Hautarzt. 2020;71:223-6. https://doi.org/10.1007/ S00105-019-04518-W.

42. Tillman WG. Herpes gestationis with hydatidiform mole and chorion epithelioma. Br Med J. 1950;1:1471. https://doi.org/10. 1136/bmj.1.4668.1471.

43. Djahansouzi S, Nestle-Kraemling C, Dall P, Bender HG, Hanstein B. Herpes gestationis may present itself as a paraneoplastic syndrome of choriocarcinoma-a case report. Gynecol Oncol. 2003;89:334-7. https://doi.org/10.1016/S0090-8258(03) 00070-2.

44. Do Valle Chiossi MP, Costa RS, Roselino AMF. Titration of herpes gestationis factor fixing to $\mathrm{C} 3$ in pemphigoid herpes gestationis associated with choriocarcinoma. Arch Dermatol. 2000;136:129-30. https://doi.org/10.1001/archderm.136.1.129-a.

45. Inani K, Meziane M, Bouyahyaoui Y, Mernissi FZ, Sekal M, Harmouch T, et al. Choriocarcinoma: a hidden face of gestational pemphigoid. Gynecol Obstet Fertil. 2014;42:357-9. https://doi. org/10.1016/j.gyobfe.2013.11.003.

46. Takatsuka Y, Komine M, Ohtsuki M. Pemphigoid gestationis with a complete hydatidiform mole. J Dermatol. 2012;39:474-6. https://doi.org/10.1111/j.1346-8138.2011.01315.x.

47. Matsumoto N, Osada M, Kaneko K, Ohara K, Noguchi D, Udagawa $\mathrm{H}$, et al. Pemphigoid gestationis after spontaneous expulsion of a massive complete hydatidiform mole. Case Rep Obstet Gynecol. 2013;2013:1-5. https://doi.org/10.1155/2013/267268.

48. Slazinski L, Degefu S. Herpes gestationis associated with choriocarcinoma. Arch Dermatol. 1982;118:425-8. https://doi.org/ 10.1001/archderm.1982.01650180059019.

49. Shornick JK, Bangert JL, Freeman RG, Gilliam JN. Herpes gestationis: clinical and histologic features of twenty-eight cases. J Am Acad Dermatol. 1983;8:214-24. https://doi.org/10.1016/ S0190-9622(83)70027-7.

50. Kolodny RC. Herpes gestationis. A new assessment of incidence, diagnosis, and fetal prognosis. Am J Obstet Gynecol. 1969;104:39-45. https://doi.org/10.1016/S0002-9378(16) 34138-2.

51. Tani N, Kimura Y, Koga H, Kawakami T, Ohata C, Ishii N, et al. Clinical and immunological profiles of 25 patients with pemphigoid gestationis. Br J Dermatol. 2015;172:120-9. https://doi.org/ 10.1111/bjd.13374.

52. Huilaja L, Mäkikallio K, Sormunen R, Lohi J, Hurskainen T, Tasanen K. Gestational pemphigoid: placental morphology and function. Acta Derm Venereol. 2013;93:33-8. https://doi.org/10. 2340/00015555-1370.

53. Montagnon CM, Tolkachjov SN, Murrell DF, Camilleri MJ, Lehman JS. Subepithelial autoimmune blistering dermatoses: clinical features and diagnosis. J Am Acad Dermatol. 2021;85:114. https://doi.org/10.1016/j.jaad.2020.11.076.

54. Semkova K, Black M. Pemphigoid gestationis: current insights into pathogenesis and treatment. Eur J Obstet Gynecol Reprod Biol. 2009;145:138-44. https://doi.org/10.1016/j.ejogrb.2009.05. 012.

55. Intong LRA, Murrell DF. Pemphigoid gestationis: pathogenesis and clinical features. Dermatol Clin. 2011;29:447-52. https:// doi.org/10.1016/j.det.2011.03.002.

56. Al Saif F, Jouen F, Hebert V, Chiavelli H, Darwish B, DuvertLehembre S, et al. Sensitivity and specificity of BP180 NC16A enzyme-linked immunosorbent assay for the diagnosis of pemphigoid gestationis. J Am Acad Dermatol. 2017;76:560-2. https://doi.org/10.1016/j.jaad.2016.09.030.
57. Powell AM, Sakuma-Oyama Y, Oyama N, Albert S, Bhogal B, Kaneko F, et al. Usefulness of BP180 NC16a enzyme-linked immunosorbent assay in the serodiagnosis of pemphigoid gestationis and in differentiating between pemphigoid gestationis and pruritic urticarial papules and plaques of pregnancy. Arch Dermatol. 2005;141:705-10. https://doi.org/10.1001/archderm. 141.6.705.

58. Sitaru C, Powell J, Messer G, Bröcker EB, Wojnarowska F, Zillikens D. Immunoblotting and enzyme-linked immunosorbent assay for the diagnosis of pemphigoid gestationis. Obstet Gynecol. 2004;103:757-63. https://doi.org/10.1097/01.AOG. 0000115506.76104.ad.

59. Ceryn J, Siekierko A, Skibińska M, Doss N, Narbutt J, Lesiak A. Pemphigoid gestationis - case report and review of literature. Clin Cosmet Investig Dermatol. 2021;14:665-70. https://doi.org/ 10.2147/ccid.s297520.

60. Fania L, Guerriero C, Ricci F, Gagliano MF, De Simone C. Herpes gestationis and oral contraceptive: case report and review of the literature. Dermatol Ther. 2017. https://doi.org/10.1111/dth. 12518.

61. Patsatsi A, Marinovic B, Murrell D. Autoimmune bullous diseases during pregnancy: solving common and uncommon issues. Int J Womens Dermatol. 2019;5:166. https://doi.org/10.1016/J. IJWD.2019.01.003.

62. Gregurek-Novak T. Topical therapy with fluorinated and nonfluorinated corticosteroids in patients with atopic dermatitis. J Eur Acad Dermatol Venereol. 2001;15:81-2. https://doi.org/10. 1046/J.1468-3083.2001.00176-5.X.

63. Rademaker M, Agnew K, Andrews M, Armour K, Baker C, Foley $\mathrm{P}$, et al. Psoriasis in those planning a family, pregnant or breastfeeding. The Australasian Psoriasis Collaboration. Australas J Dermatol. 2018;59:86-100. https://doi.org/10.1111/AJD.12641.

64. Kushner CJ, Concha JSS, Werth VP. Treatment of autoimmune bullous disorders in pregnancy. Am J Clin Dermatol. 2018;19:391-403. https://doi.org/10.1007/s40257-018-0342-0.

65. Sciascia S, Baldovino S, Ribero S, Marzano AV, Genovese G, Derlino F, et al. A systematic review of treatment options and clinical outcomes in pemphigoid gestationis. Front Med. 2020;7: 604945. https://doi.org/10.3389/fmed.2020.604945.

66. Patel PM, Jones VA, Murray TN, Amber KT. A review comparing international guidelines for the management of bullous pemphigoid, pemphigoid gestationis, mucous membrane pemphigoid, and epidermolysis bullosa acquisita. Am J Clin Dermatol. 2020;21:557-65. https://doi.org/10.1007/s40257-020-00513-3.

67. Yang A, Uhlenhake E, Murrell DF. Pemphigoid gestationis and intravenous immunoglobulin therapy. Int J Womens Dermatol. 2018;4:166-9. https://doi.org/10.1016/j.ijwd.2018.03.007.

68. Nguyen T, Alraqum E, Razzaque AA. Positive clinical outcome with IVIg as monotherapy in recurrent pemphigoid gestationis. Int Immunopharmacol. 2015;26:1-3. https://doi.org/10.1016/j. intimp.2015.02.038.

69. Killion L, Beatty P, Tierney E, Hackett C, Tobin AM, O'Brennan E. Severe pemphigoid gestationis responsive to intravenous immunoglobulins after initial treatment failure of combined oral steroids and cyclosporin. Eur J Dermatol. 2021;31:245-6. https:// doi.org/10.1684/ejd.2021.4006.

70. Boria F, Maseda R, Albízuri F, de la Calle M. Intravenous immunoglobulin therapy for gestational pemphigoid refractory to conventional treatment. Actas Dermosifiliogr. 2021;112:83-5. https://doi.org/10.1016/j.ad.2019.04.016.

71. Almeida FT, Sarabando R, Pardal J, Brito C. Pemphigoid gestationis successfully treated with intravenous immunoglobulin. BMJ Case Rep. 2018. https://doi.org/10.1136/bcr-2018-224346.

72. De la Calle M, Vidaurrázaga C, Martinez N, González-Beato M, Antolín E, Bartha JL. Successful treatment of a severe early onset case of pemphigoid gestationis with intravenous immunoglobulin 
in a twin pregnancy conceived with in vitro fertilisation in a primigravida. J Obstet Gynaecol. 2017;37:246-7. https://doi.org/ 10.1080/01443615.2016.1244809.

73. Ko BJ, Whang KU. Intravenous immunoglobulin therapy for persistent pemphigoid gestationis with steroid induced iatrogenic Cushing's syndrome. Ann Dermatol. 2014;26:661-3. https://doi. org/10.5021/ad.2014.26.5.661.

74. Hapa A, Gurpinar A, Akan T, Gokoz O. A resistant case of pemphigus gestationis successfully treated with intravenous immunoglobulin plus cyclosporine. Int J Dermatol. 2014. https://doi. org/10.1111/ijd.12128.

75. Prussick R, Ali MAM, Rosenthal D, Guyatt G. The protective effect of vitamin $\mathrm{E}$ on the hemolysis associated with dapsone treatment in patients with dermatitis herpetiformis. Arch Dermatol. 1992;128:210-3. https://doi.org/10.1001/ARCHDERM. 1992.01680120082007.

76. Tourte M, Brunet-Possenti F, Mignot S, Gavard L, Descamps V. Pemphigoid gestationis: a successful preventive treatment by rituximab. J Eur Acad Dermatol Venereol. 2017;31:e206-7. https://doi.org/10.1111/jdv.13962.

77. Leroy C, Rigot JM, Leroy M, Decanter C, Le Mapihan K, Parent AS, et al. Immunosuppressive drugs and fertility. Orphanet J Rare Dis. 2015;10:1-15. https://doi.org/10.1186/s13023-015-0332-8.

78. Chi CC, Wang SH, Charles-Holmes R, Ambros-Rudolph C, Powell J, Jenkins R, et al. Pemphigoid gestationis: early onset and blister formation are associated with adverse pregnancy outcomes. Br J Dermatol. 2009;160:1222-8. https://doi.org/10. 1111/J.1365-2133.2009.09086.X.

79. Bicocca MJ, Sperling JD, Chauhan SP. Intrahepatic cholestasis of pregnancy: review of six national and regional guidelines. Eur J Obstet Gynecol Reprod Biol. 2018;231:180-7. https://doi.org/ 10.1016/J.EJOGRB.2018.10.041

80. Reyes H, Gonzalez MC, Ribalta J, Aburto H, Matus C, Schramm $\mathrm{G}$, et al. Prevalence of intrahepatic cholestasis of pregnancy in Chile. Ann Intern Med. 1978;88:487-93. https://doi.org/10.7326/ 0003-4819-88-4-487.

81. Lee RH, Goodwin TM, Greenspoon J, Incerpi M. The prevalence of intrahepatic cholestasis of pregnancy in a primarily Latina Los Angeles population. J Perinatol. 2006;26:527-32. https://doi.org/ 10.1038/sj.jp.7211545

82. Kenyon AP, Tribe RM, Nelson-Piercy C, Girling JC, Williamson $\mathrm{C}$, Seed PT, et al. Pruritus in pregnancy: a study of anatomical distribution and prevalence in relation to the development of obstetric cholestasis. Obstet Med. 2010;3:25. https://doi.org/10. 1258/OM.2010.090055.

83. Laifer SA, Stiller RJ, Siddiqui DS, Dunston-Boone G, Whetham JCG. Ursodeoxycholic acid for the treatment of intrahepatic cholestasis of pregnancy. J Matern Fetal Med. 2001;10:131-5. https:// doi.org/10.1080/714052719.

84. Abedin P, Weaver JB, Egginton E. Intrahepatic cholestasis of pregnancy: prevalence and ethnic distribution. Ethn Health. 1999;4:35-7. https://doi.org/10.1080/13557859998173.

85. Kremer AE, Wolf K, Ständer S. Intrahepatic pregnancy cholestasis: rare but relevant. Hautarzt. 2017;68:95-102. https://doi.org/ 10.1007/s00105-016-3923-y.

86. Lammert F, Marschall HU, Glantz A, Matern S. Intrahepatic cholestasis of pregnancy: molecular pathogenesis, diagnosis and management. J Hepatol. 2000;33:1012-21. https://doi.org/ 10.1016/S0168-8278(00)80139-7.

87. Xiao J, Li Z, Song Y, Sun Y, Shi H, Chen D, et al. Molecular pathogenesis of intrahepatic cholestasis of pregnancy. Can J Gastroenterol Hepatol. 2021. https://doi.org/10.1155/2021/6679322.

88. Kirkinen P, Ylöstalo P, Heikkinen J, Mäentausta O. Gallbladder function and maternal bile acids in intrahepatic cholestasis of pregnancy. Eur J Obstet Gynecol Reprod Biol. 1984;18:29-34. https://doi.org/10.1016/0028-2243(84)90030-3.
89. Ropponen A, Sund R, Riikonen S, Ylikorkala O, Aittomäki K. Intrahepatic cholestasis of pregnancy as an indicator of liver and biliary diseases: a population-based study. Hepatology. 2006;43:723-8. https://doi.org/10.1002/hep.21111.

90. Locatelli A, Roncaglia N, Arreghini A, Bellini P, Vergani P, Ghidini A. Hepatitis $C$ virus infection is associated with a higher incidence of cholestasis of pregnancy. BJOG An Int J Obstet Gynaecol. 1999;106:498-500. https://doi.org/10.1111/j.14710528.1999.tb08305.x.

91. Paternoster DM, Fabris F, Palù G, Santarossa C, Bracciante R, Snijders D, et al. Intra-hepatic cholestasis of pregnancy in hepatitis C virus infection. Acta Obstet Gynecol Scand. 2002;81:99103. https://doi.org/10.1034/J.1600-0412.2002.810202.X.

92. Marathe JA, Lim WH, Metz MP, Scheil W, Dekker GA, Hague WM. A retrospective cohort review of intrahepatic cholestasis of pregnancy in a South Australian population. Eur J Obstet Gynecol Reprod Biol. 2017;218:33-8. https://doi.org/10.1016/j. ejogrb.2017.09.012.

93. Martineau M, Raker C, Powrie R, Williamson C. Intrahepatic cholestasis of pregnancy is associated with an increased risk of gestational diabetes. Eur J Obstet Gynecol Reprod Biol. 2014;176:80-5. https://doi.org/10.1016/j.ejogrb.2013.12.037.

94. Wikström Shemer E, Marschall HU, Ludvigsson JF, Stephansson $O$. Intrahepatic cholestasis of pregnancy and associated adverse pregnancy and fetal outcomes: a 12-year population-based cohort study. An Int J Obstet Gynaecol. 2013;120:717-23. https://doi. org/10.1111/1471-0528.12174.

95. Bergasa NV. The pruritus of cholestasis: from bile acids to opiate agonists: relevant after all these years. Med Hypotheses. 2018;110:86-9. https://doi.org/10.1016/j.mehy.2017.11.002.

96. Wongjarupong N, Bharmal S, Lim N. Never too soon: an unusual case of intrahepatic cholestasis of pregnancy at five weeks gestation. Cureus. 2020. https://doi.org/10.7759/cureus.10540.

97. Koh K, Kathirvel R, Mathur M. Rare case of obstetric cholestasis presenting in the first trimester following in vitro fertilisation. BMJ Case Rep. 2021;14: e244254. https://doi.org/10.1136/ BCR-2021-244254.

98. Meier Y, Zodan T, Lang C, Zimmermann R, Kullak-Ublick G, Meier P, et al. Increased susceptibility for intrahepatic cholestasis of pregnancy and contraceptive-induced cholestasis in carriers of the 1331T $>$ C polymorphism in the bile salt export pump. World J Gastroenterol. 2008;14:38-45. https://doi.org/10.3748/WJG. 14.38 .

99. Zhan Q, Qi X, Weng R, Xi F, Chen Y, Wang Y, et al. Alterations of the human gut microbiota in intrahepatic cholestasis of pregnancy. Front Cell Infect Microbiol. 2021. https://doi.org/10. 3389/fcimb.2021.635680.

100. Zipori Y, Bachar G, Farago N, Lauterbach R, Weissman A, Beloosesky R, et al. Vaginal progesterone treatment for the prevention of preterm birth and intrahepatic cholestasis of pregnancy: a case-control study. Eur J Obstet Gynecol Reprod Biol. 2020;253:117-20. https://doi.org/10.1016/j.ejogrb.2020.08.043.

101. Zhang X, Chen Y, Salerno S, Li Y, Zhou L, Zeng X, et al. Prediction of intrahepatic cholestasis of pregnancy in the first 20 weeks of pregnancy. J Matern Fetal Neonatal Med. 2021. https://doi. org/10.1080/14767058.2021.1911996.

102. Roszkowski I, Pisarek-Miedzińska D. Jaundice in pregnancy: II. Clinical course of pregnancy and delivery and condition of neonate. Am J Obstet Gynecol. 1968;101:500-3. https://doi.org/10. 1016/0002-9378(68)90559-0.

103. de Swiet M. Medical disorders in obstetric practice. Oxford: Blackwell Publishing; 2002.

104. EASL Clinical Practice Guidelines: management of cholestatic liver diseases. J Hepatol 2009;51:237-67. https://doi.org/10. 1016/J.JHEP.2009.04.009. 
105. Walker KF, Chappell LC, Hague WM, Middleton P, Thornton JG. Pharmacological interventions for treating intrahepatic cholestasis of pregnancy. Cochrane Database Syst Rev. 2020;7(7):CD000493. https://doi.org/10.1002/14651858.CD000 493.pub3.

106. Chappell LC, Bell JL, Smith A, Linsell L, Juszczak E, Dixon $\mathrm{PH}$, et al. Ursodeoxycholic acid versus placebo in women with intrahepatic cholestasis of pregnancy (PITCHES): a randomised controlled trial. Lancet. 2019;394:849-60. https://doi.org/10. 1016/S0140-6736(19)31270-X.

107. Hagenbeck C, Hamza A, Kehl S, Maul H, Lammert F, Keitel V, et al. Management of intrahepatic cholestasis of pregnancy: recommendations of the Working Group on Obstetrics and Prenatal Medicine-section on maternal disorders. Geburtshilfe Frauenheilkd. 2021;81:922. https://doi.org/10.1055/A-1386-3912.

108. Geenes V, Chambers J, Khurana R, Shemer EW, Sia W, Mandair $\mathrm{D}$, et al. Rifampicin in the treatment of severe intrahepatic cholestasis of pregnancy. Eur J Obstet Gynecol Reprod Biol. 2015;189:59-63. https://doi.org/10.1016/j.ejogrb.2015.03.020.

109. Rezai S, Gallo D, Payero E, Henderson CE. Adjuvant use of rifampin for refractory intrahepatic cholestasis of pregnancy. Obstet Gynecol. 2019;133:384-5. https://doi.org/10.1097/AOG. 0000000000003095.

110. Liu J, Murray AM, Mankus EB, Ireland KE, Acosta OM, Ramsey PS. Adjuvant use of rifampin for refractory intrahepatic cholestasis of pregnancy. Obstet Gynecol. 2018;132:678-81. https://doi. org/10.1097/AOG.0000000000002794.

111. Liu J, Murray AM, Mankus EB, Ireland KE, Acosta OM, Ramsey PS. In reply. Obstet Gynecol. 2019;133:385. https://doi.org/10. 1097/AOG.0000000000003096.

112. Gaudet R, Merviel P, Berkane N, Schouppe S, Cocheton JJ, Uzan $\mathrm{S}$. Fetal impact of cholestasis of pregnancy: experience at Tenon Hospital and literature review. Fetal Diagn Ther. 2000;15:191-7. https://doi.org/10.1159/000021005.

113. Williamson C, Miragoli M, Kadir SSA, Abu-Hayyeh S, Papacleovoulou G, Geenes V, et al. Bile acid signaling in fetal tissues: implications for intrahepatic cholestasis of pregnancy. Dig Dis. 2011;29:58-61. https://doi.org/10.1159/000324130.

114. Alsulyman OM, Ouzounian JG, Ames-Castro M, Goodwin TM. Intrahepatic cholestasis of pregnancy: perinatal outcome associated with expectant management. Am J Obstet Gynecol. 1996;175:957-60. https://doi.org/10.1016/S0002-9378(96) 80031-7.

115. Davies MH, Da Silva RCMA, Jones SR, Weaver JB, Elias E. Fetal mortality associated with cholestasis of pregnancy and the potential benefit of therapy with ursodeoxycholic acid. Gut. 1995;37:580-4. https://doi.org/10.1136/gut.37.4.580.

116. Lambert J. Itch in pregnancy management. Curr Probl Dermatol. 2016;50:164-72. https://doi.org/10.1159/000446087.

117. Jones SV, Ambros-Rudolph C, Nelson-Piercy C. Skin disease in pregnancy. BMJ. 2014. https://doi.org/10.1136/bmj.g3489.

118. del Carpio-Orantes L, Rosas-Lozano AL, García-Méndez S. Zika virus infection in pregnant women in a General Hospital of Veracruz, Mexico. J Matern Neonatal Med. 2020;33:3627-31. https://doi.org/10.1080/14767058.2019.1582627.

119. Stefaniak AA, Białynicki-Birula R, Krajewski PK, Matusiak $€$, Goldust M, Szepietowski JC. Itch in the era of COVID-19 pandemic: an unfolding scenario. Dermatol Ther. 2020. https://doi. org/10.1111/dth.13477.

120. Weisshaar E, Diepgen TL, Luger TA, Seeliger S, Witteler R, Ständer S. Pruritus in pregnancy and childhood-do we really consider all relevant differential diagnoses? Eur J Dermatol. 2005;15:320-31.

121. Kolitz E, Gammon L, Mauskar M. Vulvar lichen sclerosus in women of reproductive age. Baylor Univ Med Cent Proc.
2021;34:349-51. https://doi.org/10.1080/08998280.2021.18850 93.

122. Estevinho C, Soares E, Carvalho AP, Costa F. Vulvar pruritus. BMJ Case Rep. 2020;13: e240048. https://doi.org/10.1136/ bcr-2020-240048.

123. Akarsu S, Ozbagcivan O, Ilknur T, Semiz F, Inci BB, Fetil E. Xerosis cutis and associated co-factors in women with prurigo nodularis. An Bras Dermatol. 2018;93:671-9. https://doi.org/10. 1590/abd1806-4841.20187127.

124. Sakai S, Kikuchi K, Satoh J, Tagami H, Inoue S. Functional properties of the stratum corneum in patients with diabetes mellitus: similarities to senile xerosis. Br J Dermatol. 2005;153:319-23. https://doi.org/10.1111/j.1365-2133.2005.06756.x.

125. Seité S, Khemis A, Rougier A, Ortonne J. Importance of treatment of skin xerosis in diabetes. J Eur Acad Dermatol Venereol. 2011;25:607-9. https://doi.org/10.1111/j.1468-3083.2010. 03807.x.

126. Stefaniak A, Chlebicka I, Szepietowski J. Itch in diabetes: a common underestimated problem. Adv Dermatol Allergol. 2019. https://doi.org/10.5114/ada.2019.89712.

127. Nikolajuk-Stasiuk J, Lapinski TW. The influence of hepatitis B virus (Hbv) or hepatitis $\mathrm{C}$ virus (Hcv) infections on the pregnancy course. Ginekol Pol. 2021;92:30-4. https://doi.org/10. 5603/GP.A2020.0139.

128. Chi C, Wang S, Wojnarowska F, Kirtschig G, Davies E, Bennett C. Safety of topical corticosteroids in pregnancy. Cochrane Database Syst Rev. 2015;2015(10):CD007346. https://doi.org/ 10.1002/14651858.CD007346.PUB3.

129. Chi CC, Wang SH, Mayon-White R, Wojnarowska F. Pregnancy outcomes after maternal exposure to topical corticosteroids: a UK population-based cohort study. JAMA Dermatol. 2013;149:1274-80. https://doi.org/10.1001/jamadermatol.2013. 5768.

130. Gilbert C, Mazzotta P, Loebstein R, Koren G. Fetal safety of drugs used in the treatment of allergic rhinitis: a critical review. Drug Saf. 2005;28:707-19. https://doi.org/10.2165/00002018200528080-00005.

131. Moretti ME, Caprara D, Coutinho CJ, Bar-Oz B, Berkovitch M, Addis A, et al. Fetal safety of loratadine use in the first trimester of pregnancy: a multicenter study. J Allergy Clin Immunol. 2003;111:479-83. https://doi.org/10.1067/mai.2003.130.

132. Schatz M, Petitti D. Antihistamines and pregnancy. Ann Allergy Asthma Immunol. 1997;78:157-9. https://doi.org/10.1016/ S1081-1206(10)63382-0.

133. Källén B. Use of antihistamine drugs in early pregnancy and delivery outcome. J Matern Neonatal Med. 2002;11:146-52. https://doi.org/10.1080/jmf.11.3.146.152.

134. Hansen C, Desrosiers TA, Wisniewski K, Strickland MJ, Werler MM, Gilboa SM. Use of antihistamine medications during early pregnancy and selected birth defects: The National Birth Defects Prevention Study, 1997-2011. Birth Defects Res. 2020;112:1234-52. https://doi.org/10.1002/bdr2.1749.

135. Andersson NW, Torp-Pedersen C, Andersen JT. Association between fexofenadine use during pregnancy and fetal outcomes. JAMA Pediatr. 2020. https://doi.org/10.1001/jamapediatrics. 2020.1316

136. Andersson NW, Poulsen HE, Andersen JT. Desloratadine use during pregnancy and risk of adverse fetal outcomes: a Nationwide cohort study. J Allergy Clin Immunol Pract. 2020;8:1598605. https://doi.org/10.1016/j.jaip.2020.02.017.

137. Zhang M, Goyert G, Lim HW. Folate and phototherapy: what should we inform our patients? J Am Acad Dermatol. 2017;77:958-64. https://doi.org/10.1016/j.jaad.2016.10.016.

138. Park KK, Murase JE. Narrowband UV-B phototherapy during pregnancy and folic acid depletion. Arch Dermatol. 
2012;148:132-3. https://doi.org/10.1001/archdermatol.2011. 1614.

139. Kebria AS, Hosseini M, Khafri S. The effect of narrowband ultraviolet B phototherapy on serum folate level. Casp J Intern Med. 2021;12:180-3. https://doi.org/10.22088/cjim.12.2.180.

140. Ortonne J, Arellano I, Berneburg M, Cestari T, Chan H, Grimes $\mathrm{P}$, et al. A global survey of the role of ultraviolet radiation and hormonal influences in the development of melasma. J Eur Acad Dermatol Venereol. 2009;23:1254-62. https://doi.org/10.1111/J. 1468-3083.2009.03295.X.

141. Pinsky L, Digeorce AM. Cleft palate in the mouse: a teratogenic index of glucocorticoid potency. Science. 1965;147:402-3. https://doi.org/10.1126/science.147.3656.402.

142. Park-Wyllie L, Mazzota P, Pastuszak A, Moretti ME, Beique L, Hunnisett L et al (2000) Birth defects after maternal exposure to corticosteroids: prospective cohort study and meta-analysis of epidemiological studies. Teratology 62:385-392.

143. Gur C, Diav-Citrin O, Shechtman S, Arnon J, Ornoy A. Pregnancy outcome after first trimester exposure to corticosteroids: a prospective controlled study. Reprod Toxicol. 2004;18:93-101. https://doi.org/10.1016/j.reprotox.2003.10.007.

144. Dalziel SR, Walker NK, Parag V, Mantell C, Rea HH, Rodgers A, et al. Cardiovascular risk factors after antenatal exposure to betamethasone: 30 -year follow-up of a randomised controlled trial. Lancet. 2005;365:1856-62. https://doi.org/10.1016/S01406736(05)66617-2.

145. Øtensen M, Khamashta M, Lockshin M, Parke A, Brucato A, Carp H, et al. Anti-inflammatory and immunosuppressive drugs and reproduction. Arthritis Res Ther. 2006;8:1-19. https://doi. org/10.1186/ar1957.

146. Prévot A, Martini S, Guignard JP. In utero exposure to immunosuppressive drugs. Biol Neonate. 2002;81:73-81. https://doi.org/ $10.1159 / 000047187$.

147. Moskovitz DN, Bodian C, Chapman ML, Marion JF, Rubin PH, Scherl E, et al. The effect on the fetus of medications used to treat pregnant inflammatory bowel-disease patients. Am J Gastroenterol. 2004;99:656-61. https://doi.org/10.1111/j.1572-0241. 2004.04140.x.
148. Nørgård B, Pedersen L, Christensen LA, Sørensen HT. Therapeutic drug use in women with Crohn's disease and birth outcomes: a Danish Nationwide Cohort Study. Am J Gastroenterol. 2007;102:1406-13. https://doi.org/10.1111/j.1572-0241.2007. 01216.x.

149. Cleary BJ, Källén B. Early pregnancy azathioprine use and pregnancy outcomes. Birth Defects Res Part A Clin Mol Teratol. 2009;85:647-54. https://doi.org/10.1002/BDRA.20583.

150. McCormack PL. Omalizumab: a review of its use in patients with chronic spontaneous urticaria. Drugs. 2014;74:1693-9. https:// doi.org/10.1007/s40265-014-0290-9.

151. Losappio LM, Mirone C, Schroeder JW, Scibilia J, Balossi L, Pastorello EA. Omalizumab use in chronic spontaneous urticaria during pregnancy and a four years' follow-up: a case report. Case Rep Dermatol. 2020;12:174-7. https://doi.org/10.1159/00050 9179.

152. Namazy J, Cabana MD, Scheuerle AE, Thorp JM, Chen H, Carrigan G, et al. The Xolair Pregnancy Registry (EXPECT): the safety of omalizumab use during pregnancy. J Allergy Clin Immunol. 2015;135:407-12. https://doi.org/10.1016/j.jaci.2014. 08.025 .

153. Namazy JA, Blais L, Andrews EB, Scheuerle AE, Cabana MD, Thorp JM, et al. Pregnancy outcomes in the omalizumab pregnancy registry and a disease-matched comparator cohort. J Allergy Clin Immunol. 2020;145:528-536.e1. https://doi.org/ 10.1016/j.jaci.2019.05.019.

154. Jacob SE, Steele T. Corticosteroid classes: a quick reference guide including patch test substances and cross-reactivity. J Am Acad Dermatol. 2006;54:723-7. https://doi.org/10.1016/J.JAAD. 2005.12.028.

155. British Association of Dermatologists. The British Association of Dermatologists' information on topical corticosteroids-established and alternative proprietary names, potency, and discontinuation. London: British Association of Dermatologists; June 2015. https://www.bad.org.uk/shared/get-file.ashx?id=3427\& itemtype $=$ document. Accessed 17 Oct 2021. 